\title{
DO PRUITT-IGOE AO WORLD TRADE CENTER \\ Planejando a Ex/Implosão do (Pós)Modernismo
}

\author{
CLARA IRAZÁBAL
}

R E S U M O O artigo discute, em meio a conceitos de pós-modernidade, as semelhanças na destruição de dois marcos da arquitetura moderna: o conjunto residencial Pruitt-Igoe (PI) e o World Trade Center (WTC). Argumenta que a destruição, tanto do PI como do WTC, deveu-se não apenas à questão fisica (no PI, uma destruição planejada pela sociedade, e no WTC, uma destruição por ela não planejada); pelo contrário, a queda de ambos os edifícios seria uma materialização do fim do pensamento modernista, do qual seriam simbolos. Contrariamente ao que foi dito a respeito do 11/09/2001, propóe que naquela hora o mundo já havia mudado e que a destruição do WTC foi apenas a representação da mudança. Seguindo essa argumentação, o artigo propóe inovações no campo do planejamento e da arquitetura, assim como novas concepçóes para espaços contemporâneos, a exemplo dos projetos do novo WTC.

P A L A V R A S - C H A V E Arquitetura moderna; pós-modernidade; PruittIgoe; World Trade Center.

"Um avião não pode derrubar torres de palavras (...) Elas são fabricadas de um outro tipo de poder, um poder que não se exibe, que não se faz visível ou vergonhoso, mas que é definitivamente um poder mais sutil e duradouro. Diante da violência que derruba torres aqui e ali, ou que bombardeia cidades e mata crianças, monumentos de palavras mostram um caminho alternativo."

Rafael Courtoisie, entrevistado por Rubén Wisotskia para El Nacional, 24 de novembro de 2001 (tradução da autora).

"(As)sustada diante de um sentido mais forte de destino comum pelo horror do 11 de Setembro de 2001, durante os doze meses seguintes a raça humana finalmente invocou o desejo de resolver assuntos muito difíceis encarando-os. Em debates passionais (...) ela reuniu com muito esforço suas ferramentas, discutiu meticulosamente as estratégias e estabeleceu as parcerias criativas que se mostravam necessárias para o trabalho a fazer."

Secretário-geral das Naçōes Unidas, Kofi Annan, sobre o que ele esperava ver escrito nos livros de História em quinze anos. Londres, 25 de Fevereiro de 2002.

Implodir - "estourar para dentro"; "o ato de desmoronar para um ponto interno, como que por pressão externa”.

Explodir - "desacreditar (explodir uma teoria)"; "irromper violentamente por resultado de uma pressão interna”.

Franklin Bookman Dictionary and Thesaurus.

A produção do ambiente construído tem sofrido o impacto do fim das ilusões da modernidade. Idéias modernas, baseadas na História concebida como um caminho linear do desenvolvimento humano e progresso contínuo, assim como a razão - expressa 
através de planos e projetos - como uma resposta clara aos problemas humanos não têm cumprido com as expectativas de solucionar a maioria dos problemas humanos, sendo que, em alguns casos, serviram mesmo para agravá-los. Dificilmente em outros casos o fim das ilusões hegemônicas modernas se mostrou tão evidente como no colapso físico do complexo de habitação popular Pruitt-Igoe (PI, Saint Louis, 1972) e, recentemente, do World Trade Center (WTC, Nova York, 2001). Esses eventos se tornaram drásticas metáforas das explosões e implosões de teorias e práticas da arquitetura e urbanização que marcam nossa era, ainda com algumas consequiências locais e globais imprevistas. Baseado na destruição desses dois prédios renomados, esse artigo busca refletir no sentido e transcendência da aplicação da (pós)modernidade na produção, destruição e reprodução do ambiente construído.

Este artigo revê, inicialmente, o fracasso do modelo PI, sua crítica local e sua aplicação a outras experiências. Em seguida, discute o fracasso inerente ao modelo WTC, sua revisão tanto local quanto no exterior, e questiona sua revalidação no mundo atual - por exemplo, sua afirmação e seu feroz desdobramento no McWorld. Poder-se-ia argumentar que o fracasso do PI não pode ser comparado à destruição do WTC. Por um lado, a demolição do PI foi algo "planejado" pelo consenso da sociedade; já a destruição do WTC não foi planejada (é claro que foi planejada, mas não pela sociedade que fazia uso dos edifícios). Pode ainda ser argumentado que a fundamentação racional para o colapso do PI foi corrigir algo que tinha sido mal feito - isto é, fazer o bem - enquanto a queda do WTC foi uma forma de destruir algo que tinha sido bem feito - isto é, fazer o mal. Há verdades parciais valiosas nessas afirmações. Mas por mais que possa doer, esse artigo propóe que seria muito ingênuo e chauvinista encarar os eventos assim. Portanto, colocando os eventos do 11/9/2001 como o pano de fundo sobre o qual podemos problematizar o campo do planejamento, este artigo pretende ainda revisar o status quo no campo do planejamento urbano e desvendar algumas novas perspectivas para essa entrada agitada do século 21.

Contrariamente a percepções populares e oficiais e representações que alegam que o mundo mudou no 11/9, este artigo enfatiza a idéia de que no 11/9 o mundo já havia mudado. Devido ao impacto das transformações históricas no campo do planejamento, há a necessidade de uma reconstrução da arqueologia intelectual do planejamento, a remoção do entulho teórico e prático e a reconstrução, partindo do zero, num sentido filosófico. O desenvolvimento de uma nova teoria visando a compreensão da nova história é um esforço corrente que demanda tempo e requer esforço coletivo. Enquanto isso, a tarefa pode ser estrategicamente apoiada pela desestabilização das instituições planejadoras. Muita arrogância e complacência dentro do campo do planejamento e entre planejadores tem tido uma participação importante no baixo rendimento das respostas do planejamento aos desafios socioespaciais. Enquanto condições estruturais mais amplas são difíceis de transformar e só podem ser alteradas a longo prazo, as atitudes institucionais do planejamento podem ser submetidas a mudanças imediatas e eficientes. $\mathrm{O}$ artigo termina com sugestôes para atingir tais mudanças na educação e prática do planejamento, além de recomendaçôes para a reconstrução de Manhattan. 


\section{PRUITT-IGOE: O FRACASSO DO MODELO, SUA REVI- SÃO LOCAL E APLICAÇÃO A OUTRAS EXPERIÊNCIAS}

O influente crítico de arquitetura e historiador Charles Jencks, em seu livro The language of postmodern Achitecture, diz que "podemos situar com precisão temporal a morte da Arquitetura Moderna". De acordo com o autor, "a arquitetura moderna morreu repentinamente e com uma sonora explosão (...) em St. Louis, Missouri, a 15 de Julho de 1972, às 15:32 horas (aproximadamente), quando vários blocos do infame Pruitt-Igoe foram dinamitados (...) pondo um fim ao seu sofrimento. Bum, bum, bum” (1981, p.9). Três décadas após esse evento icônico na história da arquitetura, é impressionante lembrar que o PI, projeto de habitação popular de 3.000 unidades, construído entre 1952 e 1955, exemplificou a arquitetura abstrata e o planejamento modernos. Seu projeto, assinado por um dos mais preeminentes arquitetos do país, Minuro Yamasaki, seguiu os princípios de planejamento de Le Corbusier e dos Congressos Internacionais de Arquitetura Moderna, e foi saudado como um exemplo do novo iluminismo. O PI chegou a ganhar prêmios do Instituto Americano de Arquitetos quando foi desenhado, em 1951.

O PI era uma construção alta, um projeto de moradia para pessoas de baixa renda, feito para substituir as envelhecidas casinhas enfileiradas. O complexo era formado por 35 blocos de onze andares, num terreno de aproximadamente 24 hectares, ${ }^{1}$ acomodando cerca de 15.000 pessoas. Ruas convencionais, jardins e espaços semiprivativos foram substituídos, neste complexo, por ruas separadas para circulação veicular e de pedestres, e também por espaços separados por diferentes funçôes como playground, área de lavanderia e creche. O estilo arquitetônico purista do PI tinha o propósito de influenciar o comportamento de seus habitantes, supostamente propiciando uma conduta virtuosa. Este objetivo era influenciado pelo determinismo ambiental, com a idéia de que a arquitetura e o planejamento apenas, tidos como meras respostas físicas a problemas sociais complexos, poderiam superar tais problemas e transformar a sociedade.

Os arquitetos e planejadores da época, juntamente com os governos local e federal, não tomaram a decisão de dinamitar o complexo por conta própria. Ao invés disso, investiram imensos esforços e recursos na tentativa de salvá-lo. Foram os habitantes do PI que, sistematicamente, vandalizaram as construções até chegar ao ponto de, em janeiro de 1970 , serem tantas as janelas quebradas que fizeram com que a perda de calor provocasse o congelamento do encanamento. Os canos se romperam e causaram estragos na instalação elétrica, deixando os moradores sem luz e sem aquecimento. A essa altura, os habitantes tiveram que ser evacuados. Dois anos depois, o complexo foi dinamitado. Sua demolição precedeu aquilo que viria a acontecer com vários projetos similares no país.

No PI, os moradores foram suspensos no ar em edifícios de onze andares para manter o térreo e o primeiro andar livres para as atividades comunitárias. Os prédios possuíam também corredores comuns a cada três andares, para lavanderia, depósito de materiais e lixo e cômodos compartilhados. Ocupado predominantemente por famílias de pais solteiros vivendo de seguro desemprego, o projeto mostrou-se um desastre. Os ambientes comunitários, que eram dissociados das unidades, tornaram-se perigosos. Logo estavam cobertos com cacos de vidro e lixo. As caixas de correio no térreo foram vandalizadas. Os corredores, saguões, elevadores e escadas eram lugares perigosos para transitar e cobertos de pichaçôes, lixo e dejetos humanos. Os elevadores, lavanderias e cômodos comunitários foram vandalizados, e o lixo acumulava-se ao redor de dutos não-operantes. Mulheres tinham que se reunir em grupos para levar seus filhos à escola
1 N.T.: no original, 60 acres. 
2 N.T.: no original, conductism; condutivismo é uma forma pouco usada de behaviorismo (Dicionário Houaiss). ou sair para fazer compras. O projeto nunca atingiu mais do que $60 \%$ de ocupação (MacDonald, 1996, p.13).

Quando pessoas desempregadas eram trazidas para o complexo PI, elas se institucionalizavam como desempregados. O efeito era que o resto da sociedade começava a percebê-los efetivamente como pessoas não-empregáveis. Então, sem esperanças, eram abandonados à própria sorte como sujeitos amarrados em uma espiral descendente de problemas sociais. Ao contrário das expectativas do arquiteto responsável, as torres de habitação popular do PI sofreram 17 anos de vandalismo por alguns de seus residentes, e milhões de dólares foram dilapidados em tentativas fracassadas de mantê-las habitáveis.

Do ponto de vista do planejamento, quais foram algumas das concepções que se mostraram erradas no projeto do PI? As concepções fracassadas da arquitetura e planejamento modernistas, bem sintetizadas pelos CIAMs, haviam sido amplamente estabelecidas, pelo menos no Ocidente. $\mathrm{Na}$ época do nascimento do projeto, várias tendências da cultura ocidental, incluindo a inevitabilidade do progresso na história humana e a melhora significativa na qualidade de vida, através dos vários avanços tecnológicos e científicos, deram forma ao ethos moderno. O PI simbolizava esses ideais/mitos da modernidade. Hoje, o determinismo ambiental que inspirou sua arquitetura está fortemente desacreditado e é percebido como incrivelmente ingênuo. Na época, no entanto, a noção não só era amplamente aceita como era também fundamentada em doutrinas filosóficas prestigiadas como o racionalismo, o pragmatismo e o condutivismo. ${ }^{2}$ Além disso, o racionalismo e o pragmatismo da arquitetura e planejamento modernos fizeram desse complexo o produto de um processo de "cima para baixo". Com o vandalismo do PI e sua subseqüente demolição, essas idéias e mitos modernistas foram postos em dúvida.

Os prédios altos do PI pareciam ótimos em teoria, mas mostraram-se inabitáveis na prática. Muitos estudos têm analisado seu fracasso e o de outros projetos similares, além de seu devastador efeito sobre as minorias, as populações pobres dos EUA. Um dos mais conhecidos exemplos é um estudo feito por Oscar Newman, na obra Defensible space (1972). Newman argumentou que a falta de ambientes semiprivados, controlados e controláveis, os corredores longos e anônimos, assim como a falta generalizada de personalidade da arquitetura do complexo PI e de projetos similares contribuíram para a maior incidência de crimes nesses ambientes do que em outros projetos urbanos de realidades sociais similares, mas com características espaciais diferentes. O estudo de Newman conclui que os residentes mantinham, controlavam e se identificavam com aquelas áreas nitidamente demarcadas como deles. Espaços compartilhados por apenas duas famílias eram bem mantidos, enquanto os corredores divididos por vinte famílias e os elevadores, saguões e escadas compartilhados por 150 famílias eram desastrosos - não evocavam sentimentos de identidade ou qualquer forma de controle. Tais locais públicos anônimos tornavam impossível que os moradores chegassem a um acordo sobre o que seria considerado um comportamento aceitável nessas áreas, ou desenvolvessem ou exercessem um sentido de propriedade, ou a capacidade de diferenciar um morador de um intruso.

Outros analistas alegaram que os projetistas erraram em não incluir no projeto informaçôes específicas dirigidas aos futuros moradores, aos bombeiros, policiais, entregadores e responsáveis pela manutenção. Se os clientes e os projetistas do PI tivessem "modelado" os usuários, e então utilizado tais usuários no processo de projeção, a construção poderia ainda existir até hoje. Incluir o grupo apropriado de usuários no processo de criação de um projeto é crucial para o gerenciamento de risco do projeto (Gause \& Lawrence, 1999). De acordo com essas noções amplamente aceitas no planeja- 
mento, a incorporação de futuros usuários e a adoção de critérios de espaço defensivo em projetos podem não somente reduzir o índice de criminalidade e estimular o reinvestimento privado como também promover e manter a integração econômica e racial, além de contribuir para criar uma forma barata de produzir moradia popular.

Será que os arquitetos e planejadores de hoje aprenderam as lições do PI? Poderíamos, meio precocemente, responder que sim, porque nenhum planejador ou arquiteto ocidental ousaria pensar em construir algo similar nos dias de hoje... pelo menos, não nos EUA ou na Europa Ocidental. Mas é quase assustador ver cidades do "terceiro mundo", particularmente na Ásia, serem ocupadas por projetos neo-Pruitt-Igoe com concepção de tipo ocidental. Este processo fez que a teórica cultural Jane M. Jacobs fizesse uma crítica pós-colonial aos edifícios altos (Jacobs, 2000). Serão esses prédios residenciais altos apropriados para aquelas sociedades, contrariamente à sociedade americana? Sua tipologia permitirá a criação de cidades mais habitáveis naquelas regiões? São ambientalmete sustentáveis? Alguns arquitetos e planejadores urbanos têm dito que as pessoas desses países reivindicam conjuntos residenciais verticalizados e, portanto, estão recebendo o que pediram. Uma questão ética surge: podem os projetistas profissionais fazer isso de forma ética, mesmo estando conscientes das conseqüências negativas desta tipologia? Serão os desejos dos asiáticos de construir PIs, se isto for realmente fato, originários de uma interpretação genuína da realidade e de suas necessidades, ou estarão eles sendo inconscientemente guiados pelos desejos implantados pela hegemonia dos ideais modernistas em geral, e do imaginário americano em particular?

Essas questôes podem e devem ser o assunto de outros estudos. Para o propósito deste artigo, é fundamental colocar que o modelo da arquitetura e do planejamento modernistas objetivados no complexo PI explodiu nos dois sentidos associados ao termo no Franklin Bookman Dictionary and Thesaurus: a teoria moderna subjacente foi levada a descrédito, devido à ingenuidade inerente às doutrinas do racionalismo, do pragmatismo e do condutivismo; e literalmente foi demolido violentamente como resultado de uma pressão interna, isto é, dos problemas sociais reais que o complexo reuniu e intensificou para seus próprios residentes.

\section{WORLD TRADE CENTER: O FRACASSO DO MODELO, SUA REVISÃO E... SEU RETORNO?}

O arquiteto, tanto do PI quanto do WTC, foi o mesmo: Minuro Yamasaki (19121986). ${ }^{3}$ Seu primeiro projeto significativo foi o PI, para o qual ele projetou simples estruturas modernistas de concreto. Ele também desenhou vários sofisticados aeroportos internacionais, e foi o responsável pelo projeto das torres do WTC, com aproximadamente 408 metros de altura. Seguindo, numa coincidência perversa, o destino das torres PI, as torres do WTC também foram destruídas, dessa vez num ataque terrorista em 11 de setembro de 2001, após dois aviōes comerciais colidirem com elas. ${ }^{4} \mathrm{~A}$ imprensa internacional rapidamente declarou que o mundo mudou às $10 \mathrm{~h} 28$ da manhã do dia 11 de setembro de 2001, quando as torres ruíram. E se a arquitetura modernista morreu no dia 15 de julho de 1972, às 3 h32 da tarde, então a pós-modernidade nasceu em 11 de setembro de 2001, às $10 \mathrm{~h} 28$ da manhã.

O WTC era um complexo de edifícios ao redor de uma praça central em Nova York. As qualidades estéticas do complexo eram inferiores às do Empire State, do edifício
3 Yamasaki era um arquiteto americano, nascido em Seattle, Washington, um nipo-americano de segunda geração. De um passado pobre, ele pagou seus estudos na Universidade de Washington trabalhando numa fábrica de enlatar salmão. Depois de se mudar para Nova York na década de 1930, ele conseguiu um emprego na firma de Shreve, Lamb e Hermon, projetistas do edifício Empire State.

4 Não foi a primeira vez que o simbolismo do WTC atraiu terroristas. Em 26 de fevereiro de 1993, uma bomba colocada por terroristas explodiu na garagem do subsolo da torre norte. Seis pessoas morreram e mais de mil ficaram feridas. Seis conspiradores islâmicos foram condenados pelo crime a 240 anos de prisão cada um, em 1997 e 1998. 
5 NT.: no original, 10.000 . 000 pés.

6 N.T.: no original, 100 pés.

7 As torres mantiveram 0 recorde de altura por pouco tempo. Enquanto estavam sendo concluídas, as obras da torre Sears, em Chicago, já haviam iniciado. Essa torre atingiu a marca de, aproximadamente, 435 metros. Desde a destruição das torres, o Empire State voltou a ser o edifício mais alto de Nova York, depois de quase trinta anos como o terceiro mais alto.
Chrysler e do Rockefeller Center. Sua presença agressiva na parte sul de Manhattan e sua simplicidade formal fizeram do complexo uma das mais marcantes implementações da ética arquitetônica de Le Corbusier, do minimalismo de Mies van der Rohe, assim como da expressão seminal das tendências gótico-modernistas de Yamasaki (Segre, 2001). Construído no início da década de 1970 sob os auspícios da semi-autônoma Port Authotity of New York e New Jersey, o WTC era formado por sete edifícios, mas sua parte mais notável eram as torres gêmeas. As torres do WTC repetiam por 110 andares uma estrutura em filigrana de aço, e possuíam aproximadamente 3.000.000 de metros quadrados $^{5}$ para aluguel de escritório. De acordo com Jencks, "esta é a repetição extrema do Capitalismo Tardio" (Jencks, 1980 63, do autor). Quando as torres foram completadas em 1972 (torre um) e 1973 (torre dois), eram os dois edifícios mais altos do mundo, 30 me$\operatorname{tros}^{6}$ mais altos que o Empire State. ${ }^{7} \mathrm{O}$ WTC se tornou um símbolo de Nova York não só devido ao seu tamanho desproporcional mas também porque, em qualquer dia comum, cerca de 50.000 pessoas trabalhavam em suas torres.

$\mathrm{O}$ WTC estava sendo construído quando o PI foi destruído, depois que duras críticas à arquitetura e urbanismo modernistas haviam já sido publicadas e amplamente reconhecidas e articuladas por Jane Jacobs e outros. O wTC sintetizava todos os aspectos que essa autora criticava. Em seu livro clássico, The Rise and Fall of Great American Cities (1964), Jacobs louvava as ruas de Greenwich Village, a apenas alguns quarteirões do WTC, como preciosos espaços capazes de nutrir um sentido de lugar, comunidade e diversidade. As torres de Yamasaki, por outro lado, eram a mais evidente representação das torres de Le Corbusier, isoladas na paisagem. A fascinação moderna pela tecnologia, assim como sua exploração, atingiram sua altura máxima nas torres. Então, além das críticas sociais e estéticas, sua arquitetura moderna também foi questionada por sua relação sem mediação com a especulação imobiliária ao se tornar um símbolo do capitalismo ocidental.

Desde seu surgimento, o WTC foi um símbolo arrogante de poder. As torres foram criticadas desde sua construção. Houve uma extensa controvérsia sobre a segurança das torres em caso de emergências. Yamasaki sofreu ataques terríveis pela imprensa especializada e pela imprensa popular. O Corpo de Bombeiros de Nova York protestou alegando que seria impossível combater incêndios no prédio e tentou impedir sua construção, sem sucesso, como também tentaram várias outras agências e associações profissionais. Os edifícios foram erguidos em porte e altura muito acima do permitido pelos códigos municipal e de zoneamento. No entanto, o Port Authority of New York, uma agência quase governamental com poderes excepcionais, herdados do regime de Robert Moses, foi especificamente contra a sujeitação do WTC ao código de zoneamento de Nova York. As torres eram significativamente fora da escala de qualquer outra construção em Manhattan e eram consideradas pela Port Authority um símbolo de poder. Os setores imobiliários, de construção e financeiro eram também fortes defensores do projeto (Cryptome, 2002). O grosso do trabalho foi feito por um dos charlatães comerciais de Nova York, bem versado na prática imobiliária de maximizar o uso da terra.

As imensas torres gêmeas funcionaram, no palco de Manhattan, como grandes âncoras para a cidade. Desde aproximadamente a virada do século, os arranha-céus de Nova York subiram às alturas do capitalismo global, escalando acentuadamente durante as duas Guerras Mundiais e a Guerra Fria. O arranha-céu virou um símbolo dos valores americanos e do capitalismo global em particular. Desde então, arranha-céus têm tomado a imaginação de cidades, conselhos e corporaçóes no mundo inteiro. Esta tipologia migrou de Chicago e Nova York para países que tentaram seguir os passos americanos e su- 
bir no bonde da globalização econômica. Arranha-céus muito mais altos do que o WTC incluem o Centro Financeiro Mundial de Shanghai (aproximadamente 452 metros) e a torre Center of India em Katangi (aproximadamente 666 metros). ${ }^{8}$

Como uma tipologia, o arranha-céu traz um status econômico e político de atração global. Através dele, tensões entre o local e o global em cidades de todo o mundo eram expressas pela produção de ambientes tradicionais/modernos/pós-modernos híbridos. A tipologia do arranha-céu sinaliza uma absorção cultural de tendências da globalização que encontram pouca resistência entre as elites do governo, do planejamento e do projeto dessas cidades. Além disso, essas elites locais são os principais instrumentos pelos quais essas cidades sofrem uma transformação que visa aumentar a atratividade para o capital nacional e estrangeiro, enquanto instalam mecanismos de exclusão social, econômica e espacial para a maioria de seus cidadãos. Arranha-céus são construções simbólicas deliberadamente estabelecidas como ferramentas de hegemonia através das quais uma pequena parcela exerce controle político, econômico e cultural sobre sua sociedade num mundo globalizado (Irazábal, 2003).

Reconstruir será o novo passo. Mas como o Baixo Manhattan deverá ser reconstruída? Surge um debate sobre planejamento urbano, com alguns especialistas clamando pelo fim dos arranha-céus, oferecendo uma alternativa para refazer a orla de Nova York numa escala mais modesta, o que é a antítese da cultura urbana de grandes prédios. No entanto, há grandes perspectivas de competição sobre como reconstruir o Baixo Manhattan que apóiam a preservação do status quo e da cultura (e culto) dos arranha-céus. Além dos pontos de estilo e simbolismo arquitetônico, há também forças do mercado imobiliário que, nos estágios preliminares de projeto da reconstrução do WTC, ameaçaram tomar conta. O que deve se esperar e fazer para reviver um ícone arquitetônico global? (School of Journalism and the Congress for the New Urbanism, 2001).

Vários arquitetos renomados, como Norman Foster e Richard Rogers, acreditam que a implosão das torres gêmeas do WTC não significa o início de uma nova era na arquitetura (Glancey, 2001). Sua visão é de que a tipologia do arranha-céu vai prevalecer. Planejadores urbanos tendem a pensar diferentemente de arquitetos, pelo menos diferente das "estrelas", sobre as consequiências espaciais do 11/9. O planejador urbano e acadêmico Peter Marcuse prevê que "a construção de glamorosos e cada vez mais altos arranhacéus vai parar". Ele prevê uma maior descentralização das grandes cidades e um subseqüente aumento no recurso a paredes e divisōes, uma redução e maior controle de viagens pessoais, além de mais ênfase na comunicação eletrônica. Para ele, as corporações multinacionais podem mudar seus padrōes espaciais para favorecer áreas mais afastadas. Ele também antecipa o aumento de tendências que antecedem o ataque ao WTC, como uma maior polarização socioespacial entre cidade e subúrbio e, dentro das cidades, a criação de um maior número de comunidades e cidadelas fechadas por muros, além de espaços públicos se tornando cada vez menos públicos - sujeitos a uma supervisão maior, portanto mais controlados (Marcuse, 2001, p.16).

Sejam quais forem os tipos de desenvolvimento que surgirem, parece claro que, com a queda das torres, o modelo de arquitetura e planejamento modernos representado pelo WTC tanto explodiu como implodiu - de acordo com as definições atribuídas aos termos pelo Franklin Bookman Dictionary and Thesaurus. Explodiu porque a teoria por trás do complexo foi desacreditada devido a sua excessiva ênfase na monumentalidade e simbolismo do poder econômico se sobrepondo à necessidade do povo; e também porque ruiu violentamente por resultado de uma pressão interna. O WTC também implodiu por cau-
8 N.T.: no original, 1.509 pés e 2.222 pés, respectivamente. 
9 Pós-modernidade é o estado em que se expressa ceticismo em relação a nocões como o caminhar inevitável do progresso, ou a necessidade de continuar explorando o meio ambiente sem se preocupar com 0 efeito a longo prazo. Pósmodernidade indica uma descrenca em teorias universais, a suspeita generalizada da autoridade e suas grandiosas narrativas, e uma preocupação de encorajar diversidade e diferença (Sim, 1999).

100 pós-fordismo enfatiza a fragmentação do mercado em nichos e a "produção do consumo" (Baudrillard, 1975). A sociedade pós-industrial se refere à transformação de economias fordistas em economias informacionais, dependentes de informação especializada e comunicação eletrônica. A sociedade do espetáculo e a cultura do consumo apontam para um mundo em que identidades são amplamente moldadas pelo marketing e pela mídia.

11 Esse subtítulo trabalha a idéia da palestra de Manuel Castells no encontro anual da Association of Collegiate Schools of Planning (ACSP) em Austin, Texas, em 1990, entitulada: "The world has changed: can planning change?".

sa de uma pressão externa - no nível material, da colisão dos aviōes, e no nível conceitual, da realidade dos problemas sociais que o complexo tanto simbolicamente quanto efetivamente (devido às operações realizadas em seu interior) causaram e espalharam no mundo.

Segundo o crítico de arquitetura e planejamento, Roberto Segre, podemos interpretar a demolição do muro de Berlim em 1989 como um fim, e a queda do WTC como um começo. O fim do muro de Berlim trouxe esperança para o fim de um mundo polarizado, posteriormente unificado na cristalização da modernidade - por exemplo, o fim do antagonismo entre capitalismo e socialismo e o estabelecimento de bases para uma democracia universal (com a unificação da Europa como a primeira concretização dessa ilusão). $\mathrm{O}$ ataque terrorista ao WTC materializou a fragmentação caótica e pós-moderna que constitui a condição mundial atual, a ambigüidade entre o real e o virtual; o fim das idéias de progresso social e material; a exacerbação das contradições entre alta tecnologia e fanatismos (religiosos ou imperialistas), e entre renda concentrada e vastos territórios de miséria (Segre, 2001).

No rastro do colapso do ethos moderno, estamos teoricamente vivendo na pós-modernidade. ${ }^{9}$ Para alguns acadêmicos, pós-modernidade representa um novo estágio do capitalismo. David Harvey, por exemplo, explica a condição da pós-modernidade pelas formas socioculturais derivadas da "crise de sobreacumulação" na economia capitalista (Harvey, 1989, p.327-8). O ataque às torres pode ser interpretado como uma agressão a um símbolo primário da hegemonia do capital global americano, e, portanto, a algumas das mais notórias e amplamente aceitas mudanças sociais da era pós-moderna: o pós-fordismo, a sociedade pós-industrial, a sociedade do espetáculo e a cultura de consumo. ${ }^{10}$

\section{O MUNDO MUDOU: O PLANEJAMENTO Pós-1 1/9 PODE MUDAR? ${ }^{11}$}

Muitos podem argumentar que o colapso do PI não pode ser comparado à queda do WTC. Para começar, a demolição do PI foi algo "planejado", foi por consenso da sociedade; já a destruição do wtc não foi planejada (claro que foi planejada, mas de outro modo) pela sociedade que usava o edifício. Pode então se argumenta que a lógica para a destruição do PI foi a de corrigir algo que havia sido mal feito, para fazer o bem; já a destruição do WTC foi para destruir algo que havia sido bem feito, para fazer o mal. Há preciosas verdades parciais nessas afirmações. Mas, doa a quem doer, esse artigo contesta o que seria outrora uma visão estreita, ingênua, chauvinista e etnocêntrica desses acontecimentos.

Benjamim Barber, em seu livro Jibad versus McWorld (1995), explicou que vivemos em um mundo interconectado que, de forma inconveniente para todo mundo, foi polarizado entre as forças da Jihad contra o McWorld. Por outro lado, Barber chama a Jihad de "as forças de tribalismo desintegral e fundamentalismo reacionário" (p.xii). Ele descreve os guerreiros da Jihad como "pessoas que detestam a modernidade - a civilização secular, científica, racional e comercial criada pelo Iluminismo já que é definida tanto por suas virtudes (liberdade, democracia, tolerância e diversidade) quanto por seus males (desigualdade, hegemonia, imperialismo cultural e materialismo)" (p.XIV). São esses males que estão causando problemas desesperantes e a ira em países do terceiro mundo e "bairros terceiro-mundistas" em países do primeiro mundo. A briga dessas pessoas, no entanto, "não é com a modernidade, mas sim com a ideologia neoliberal agressiva que procedeu em seu nome na busca por uma sociedade de mercado global que conduzisse a mais lucros 
para uns do que justiça para todos" (p.Xv). Por outro lado, Barber chama o McWorld de "as forças de modernização integrativa e globalização econômica e cultural agressiva" (p.XII). O que ocorreu nas duas últimas décadas no mundo é uma globalização assimétrica, em que o capitalismo se globalizou mas a democracia (instituiçôes e governança cívica) não. $\mathrm{O}$ capitalismo desmedido resultante tem se manifestado em práticas predatórias que causam miséria generalizada, desesperança e morte.

É dentro deste contexto polarizado de antagonismo da Jihad versus McWorld que podemos começar a compreender o ataque terrorista ao WTC. Podemos utilizar o título de um dos romances mais celebrados do Prêmio Nobel de Literatura, Gabriel Garcia Márquez, Crônica de uma morte anunciada, para rever a história recente da política norte-americana e do Oriente Médio, tentando entender o que aconteceu, quando e como. Isso deveria ser, creio eu, um exercício moral inescapável para todos que não será, no entanto, buscado aqui. Ao invés, o propósito deste artigo é localizar os eventos do 11/9 como um pano de fundo para problematizar o campo do planejamento.

Numa nova ordem mundial, vivemos uma interconexão sem precedentes. Essa condição inevitável desvalida os mitos modernos de estados-nações soberanos. Barber, por exemplo, contesta o mito americano da independência (unilateralidade, autonomia etc.) e afirma que "a construção do novo mundo que agora se faz necessário clama por uma Declaração de Interdependência”. Nesse novo mundo, o sofrimento é globalizado e democratizado:

Se não pode haver uniformidade de justiça, haverá uniformidade de injustiça; se todos não puderem compartilhar na fartura, o empobrecimento - tanto material quanto espiritual será o resultado. Essa é a dura lição da interdependência, ensinada pelos sombrios pedagogos do terror. (Barber, 1995, p. xxiv.)

A economista urbana Saskia Sassen afirma que superar o 11/9 requererá o reconhecimento de um grande "horizonte de devastações no Sul global do qual o Norte global não pode escapar", e um plano de ação para enfrentá-lo. Ela argumenta pela "necessidade de ações de governos via novos multilateralismos e internacionalismos especializados". E é bem direta ao afirmar que "é de interesse do Norte global encarar esses assuntos", no mínimo, por uma visão utilitária estrita (Sassen, 2002).

Nós, dolorosamente, vimos que as vítimas do WTC tinham rostos, nomes, vidas e sonhos reais que foram brutalmente e injustificavelmente destruídos. Mas as vítimas inocentes da guerra no Afeganistão também tinham, ou então as vítimas inocentes da guerra no Iraque. Nós vivemos em um mundo interconectado e se nós, planejadores e arquitetos, temos uma sensibilidade progressista e particularmente bem desenvolvida para capturar essa idéia, como gostamos de pensar, então devemos agir segundo essa compreensão em nossas vidas profissionais e acadêmicas. Agir impelidos por essa compreensão pode implicar uma abertura radical sem precedentes ao outro que podemos ainda não ter considerado. Nós, arquitetos e planejadores, que gostamos de nos ver como cada vez mais eficientes no planejamento para comunidades inclusivas para minorias, além de promover um planejamento participativo e uma democracia radical, em nossa prática tanto profissional quanto pedagógica. Mas será que essas práticas louváveis realmente resultam na melhoria tanto de um conceito como de uma práxis de um mundo interconectado? Será que a expressão popularizada "pense globalmente, aja localmente" nos limitou a visões muito paroquiais para nossas ações e idéias, ao invés de nos liberar para novas com- 
12 Outros exemplos são: a carreira armamentista e 0 projeto Guerra nas Estrelas, o desejo de sair de tratados globais de desarmamento e renovar a ameaça de um holocausto nuclear, a recusa de reconhecer as resolucões de Durban contra o coIonialismo e a escravidão, a indiferença à Cúpula Mundial de Johannesburgo sobre Desenvolvimento Sustentável e sua manipulação para prevenir um exame detalhado dos padrões de consumo do Primeiro Mundo etc. preensões mais inclusivas do novo mundo? Deveria essa expressão, tão progressista, ser posta em questão?

Eu proponho mudarmos o "pense globalmente, aja localmente" para "pense glocalmente, aja glocalmente". Isso traria implicaçōes específicas para o planejamento e o projeto. Se transcendêssemos o mito da independência e soberania do Estado-nação, como mudaria a abordagem para o projeto de memoriais, por exemplo? $\mathrm{Na}$ história recente, o memorial do Vietnã em Washington D.C. não teria sido concebido sem o reconhecimento respeitoso às vítimas vietnamitas da Guerra do Vietnã; nem teria o Museu da Tolerância em Los Angeles sido criado sem considerar as vítimas não-judias da 2a Guerra Mundial e do holocausto, ou do racismo nos Estados Unidos. Não estaríamos perpetuando a falta de compreensão se construirmos um memorial ao WTC sem considerar as vítimas afegãs da guerra subseqüente ao atentado (sem contar as vítimas do conflito Israel-Palestina, ou vítimas futuras que podem surgir das ditas "guerras contra o terrorismo" no Iraque, Colômbia e outros países)? Para alguns pode ser extremamente difícil pensar nesses termos com a atual mentalidade nacionalista e pró-guerra na qual os EUA aparentemente têm vivido. No entanto, é precisamente essa mentalidade e a política originada por ela (baseada nos mitos da independência, soberania e hegemonia militar) que devem ser desafiadas e mudadas, se quisermos realmente triunfar sobre o terrorismo.

Mas o planejamento não se resume a memoriais do passado; mais do que isso, significa ter uma visão e um direcionamento para o futuro. Que espécie de futuro nós, planejadores, podemos conceber juntos, baseados nessa noção de um mundo interconectado? Que tipos de ações devem ser tomadas a curto e longo prazo para engrenar a construção de um futuro nessas direçôes?

Com certeza nossas ações devem ser guiadas por uma ética humanista e sem concessões, que funcione tão bem em terras americanas quanto no exterior. O que será que tal ética traria para o ensino e a prática do planejamento? Para o ensino, implicaria dar mais ênfase ao ensino da ética, além do ensino tanto do planejamento local com uma visão internacional quanto do planejamento internacional em si. Essas mudanças podem talvez implicar conexōes entre a pesquisa, a educação e a participação comunitária, muito freqüentemente desconectadas por medo de se comprometer o rigor acadêmico. Na prática de planejamento, implicaria dar mais ênfase ao planejamento não somente para o local do outro, mas para o global do outro. Isso pode implicar criar um elo entre a igualdade global e a local, freqüentemente separados intencionalmente por medo de comprometer a força do ativismo local e a aderência política de grupos locais. Para educadores e profissionais da área de planejamento, reencontrar-se com a ética humanista num mundo interconectado pode significar a problematização do status quo na ação, tornando-se ativistas dos valores que carregamos em nossa área.

Somando-se a isso, para que essa problematização e conseqüente transformação do status quo seja eficiente, devemos agir tanto individualmente quanto no meio acadêmico. $\mathrm{Na}$ breve história da administração Bush, por exemplo, foram tomadas muitas decisões agressivas que afetam negativamente tanto o planejamento urbano como a comunidade global. Há vários assuntos urgentes, no entanto, nos quais a presença dos planejadores e da comunidade planejadora é pequena. Por exemplo: as conseqüências do aquecimento global sobre o meio ambiente são de uma relevância imensa para o planejamento e, no entanto, nós, como planejadores, não tomamos uma forte posição coletiva e pública contra a posição do governo dos EUA de não assinar o Tratado de Kyoto, ou tampouco fizemos pressão política ou propusemos alternativas sustentáveis. ${ }^{12}$ 
Em 1990, o sociólogo urbano e acadêmico Manuel Castells fez um discurso no Encontro Anual da ACSP em Austin, Texas, intitulado: "O mundo mudou. Pode o planejamento mudar?”. Em sua fala, identificou conexões entre mudanças macrossociais e o campo do planejamento. Argumentou que o mundo havia mudado: politicamente, com o fim do comunismo; economicamente, pela transformação da economia global e a mudança da produção em massa para a especialização flexível e produção em rede; tecnologicamente, por uma revolução informacional; cultural e socialmente, principalmente pela cultura feminista e o movimento ambientalista. Essas tendências desafiaram as noções do planejamento como uma racionalidade superior que substitui o mercado e a dinâmica individual. Elas também desafiaram a rigidez do planejamento comparada à flexibilidade dos mercados, culturas e sociedades. Por último, o mundo também mudou espacialmente com o surgimento do "espaço de fluxo" vis-à-vis o "espaço de lugares". O "espaço de fluxo", Castells propôs, trazia a necessidade de espaços mais monumentais, simbólicos, de significado e organizadores de hierarquia social, além da proliferação de novas utopias desconexas de ideologias políticas.

Se reconhecermos os argumentos de Castells, feitos em 1990, o mundo já havia mudado em 11/9/2001. ${ }^{13}$ No entanto, muitos não haviam notado, ou escolheram não fazêlo. O que os fatídicos eventos do $11 / 9$ trouxeram à tona foi a inevitável e dolorosa verdade de que o mundo havia realmente mudado. A partir do impacto das transformações históricas no campo do planejamento, Castells viu uma arqueologia intelectual de planejamento reconstruída, que parecia estar emergindo nos anos 90:

Ela é feita de uma combinação de design urbano, utopia apolítica e ênfase metodológica na performance profissional de algumas funções técnicas limitadas. Penso que essa é uma versão empobrecida do que o planejamento tem sido e deveria ser. Design urbano é um ingrediente fundamental, essencial, da nossa tradição intelectual, mas não pode suprir a única base material para a reconstrução da nossa área em face das novas mudanças históricas (...) A proposta de novas utopias ainda precisa de alguma referência, ainda que indireta, a projetos políticos que poderiam nos aproximar dos sonhos, ainda que para traí-los. Portanto, a redução do planejamento à articulação entre monumentalidade e utopia, sobrevivendo em rotinas diárias de zoneamento e modelagem estatística seria, na verdade, o primeiro passo para o seu desaparecimento nas novas terras de um admirável mundo novo de capitalismo selvagem. (1990, 12-3).

Infelizmente, temos visto a evolução no nível global dessas tendências nas últimas décadas. A construção do WTC foi a concretização dessas tendências, que reduziram o planejamento à articulação da monumentalidade ao poder. Hoje, essas tendências ameaçam alcançar um clímax raivoso na reconstrução do WTC em Nova York. Na contramão dessa posição, o que é necessário para o campo do planejamento é a corajosa remoção de entulho teórico e prático, e a reconstrução a partir do zero - em termos filosóficos. Castells diz novamente:

Um mundo novo é sempre uma terra de oportunidade. Mas somente se os atores de tal oportunidade compreenderem a transformação e tiverem a esperteza de agir por conta própria. O planejamento pode, na verdade deve, ter um novo começo histórico somente se o campo em si e nós, como seus sujeitos, formos capazes de redefinir a fundação intelectual de nossa atividade de acordo com a nova época na qual estamos entrando.

(...) Acima de tudo, um mundo novo requer uma nova compreensão e, por fim, uma nova teoria. A história das ciências mostra que inovaçōes teóricas tendem a acontecer nas fissuras
13 Aqui eu resumo as vozes dissidentes que contestam a noção oficial e popular de que o mundo mudou em 11/9/2001. Agir sobre essa noção e não instilar essa noção a outros dá liberdade ao governo americano para agir fora das leis federais e internacionais e dos processos legais tradicionais. Em uma conferência em 24 de maio de 2002, a doutora Marilyn Young discutiu a "transformabilidade" do 11/9. Para ela, há uma continuidade na política externa dos Eua: a guerra contra o comunismo, local e externa, está sendo substituída pela guerra contra terroristas islâmicos fundamentalistas (Jenks, 2002). 
dos sistemas acadêmicos. Acontece no espaço entre conhecimentos, no qual a inovação é possível porque não é sufocada pela disciplina imposta por aparatos do sistema acadêmico. Acontece no campo interdisciplinar que é o planejamento, sempre alternando entre inovação sem poder e irrelevância articulada, onde fagulhas intelectuais podem atear o fogo de uma nova teoria visando a compreensão da nova História. Assim o planejamento pode estar na vanguarda intelectual do novo mundo ao invés de ser relegado às salas dos fundos da última onda de especulação urbana. (1990, p.15-6.)

O desenvolvimento de uma nova teoria visando a compreensão da nova História é uma tarefa contínua, que exige tempo e requer um esforço coletivo. Por enquanto, a tarefa pode ser estrategicamente reforçada mexendo nas instituiçóes de planejamento.

\section{DESCENTRALIZANDO O PLANEJAMENTO}

Desde 1990, quando Castells lançou o desafio do planejamento estar na vanguarda intelectual de uma nova teoria, visando a compreensão do novo mundo, não ocorreram mudanças significativas dentro da profissão. Isso se deve em parte a dificuldades estruturais. No entanto, muita prepotência e complacência dentro do campo do planejamento e entre planejadores também têm contribuído para o problema. Enquanto as antigas condições estruturais são difíceis de serem transformadas e só podem ser modificadas a longo prazo, gerações futuras poderão colher os frutos de uma ação imediata. Aqui estão algumas sugestôes:

- Criar grupos de planejadores para observar a ação de grupos, corporações e governos em todos os níveis que afetam o planejamento. Com a American Planning Association (APA), o American Institute of Certified Planners (AICP) e a Association of Collegiate Schools of Planning (ACSP) coletando contribuiçōes anuais voluntárias, planejadores poderiam ajudar a manter os salários de ativistas do planejamento e advogados que pesquisam, questionam e, quando possível, desafiam publicamente e legalmente a ação de grupos, corporações e governos que se opõem ao bem comum glocal, do âmbito federal ao municipal. Podem haver escritórios nacionais, estaduais e locais desses grupos de vigília colaborando entre si. Esses grupos poderiam se chamar "1000 Amigos do Planejamento", a exemplo do 1000 Friends of Oregon e grupos de influência no planejamento de outras cidades e Estados. ${ }^{14}$

141000 Friends of Oregon é uma firma de advocacia do interesse público que tem exercido o papel de grupo controlador do uso de terras no Estado. Tem obtido tanto sucesso que outros Estados formaram seus próprios grupos 1000 Friends, como 01000 Friends of Minnesota.

15 Conferência Internacional da ACSA 2002 em Havana, Cuba: "Architecture, Culture and the Challenges of Globalization". 21 a 24 de junho.
- Aumentar o número de moções e manifestos coletivos públicos, referentes aos assuntos ligados ao planejamento e visando a melhoria da qualidade de vida e o bem público. Novamente, escritórios nacionais, estaduais e locais de organizaçôes de planejamento devem se tornar plataformas mais expressivas tanto para contestar políticas e práticas inapropriadas quanto para ajudar a definir outras políticas mais apropriadas.

- Organizar conferências da APA e da ACSP em locais com programas que desafiam e renovam a compreensão de mundo dessas instituições, além de seus programas de alcance educacional e de transformação. Há outras instituiçôes profissionais similares que já tomaram atitudes importantes nessa direção. Por exemplo, a ACSP deve seguir os passos da ACSA ou da Planners Network. Em junho de 2002, a ACSA realizou sua conferência anual internacional em Cuba. ${ }^{15}$ Foi a primeira vez que uma associação americana fez algo similar desde 1959. Eu tive a sorte de participar dessa conferência e acredito que a troca de idéias que gerou e as experiências que propiciou enriqueceram 
em muito a compreensão dos participantes sobre a arquitetura e o planejamento em um mundo interconectado. De sua parte, também em junho de 2002, a Planners Network realizou sua conferência anual em Holyoke, Massachusetts, uma comunidade que luta com problemas ligados à desindustrialização e a mudanças raciais/étnicas. ${ }^{16} \mathrm{~A}$ comissão organizadora assegurou a inclusão na conferência de uma série de eventos culturais étnicos (música, dança, teatro) e passeios, assim como oradores das minorias da comunidade. Assim, o programa trouxe a maior e mais compreensível aproximação da cultura latina e da pregação de grupos latinos nos EUA que poderia ser atingida no âmbito de um evento dessa espécie. Portanto, tornou-se uma importante janela para uma compreensão mútua do outro.

- Ousar reviver sonhos de planejamento, criar novas metas e tomá-las no sentido de que se tornem realidade. Em 1973, o teórico de planejamento urbano Kevin Lynch (19181984) propôs a criação de uma política urbana internacional. Ele chamou sua idéia de "um sonho maluco". Essa proposta visionária, no entanto, precisa ser revista e ter seu potencial explorado:

Uma política urbana internacional é talvez um sonho maluco, mas seria uma resposta racional ao acesso desigual aos recursos do planeta, à poluiçãa mundial, ao crescimento de metrópoles nos lugares errados e com capital inadequado, à fome de trabalhadores rurais e favelados, à imigração por desespero e, em algum nível, à trama de conflitos internacionais. Uma política urbana mundial canalizaria recursos a áreas rurais e subdesenvolvidas, direcionaria migraçōes por incentivos, criaria novas regiōes urbanas internacionais, deslocaria técnicas e recursos de nação a nação, (e) patrocinaria corporaçōes de desenvolvimento internacional. Os obstáculos políticos a essas políticas são tão claros quanto a necessidade deles." (Lynch apud Banerjee \& Southworth, 1990, p.560; grifos meus).

Para alguns, o 11/9 revelou "a fraqueza das instituições mediadoras entre o globalismo hegemônico e o localismo fragmentado, sugerindo a construção de instituições regionais" (Dallmayr, 2002). A criação de instituições como as Nações Unidas teria implicado tentativas importantes para atingir alguns dos objetivos sociais que Lynch visava, não tivesse sua eficácia sido tão freqüentemente comprometida por poderes econômicos e Estados nacionais poderosos. Recentemente, tratados internacionais para um desenvolvimento sustentável e tentativas de estabelecer um sistema judiciário internacional também fraquejaram por causa de obstáculos políticos e, no entanto, nunca a necessidade de tais políticas foi tão urgente.

- Rever a filosofia e a racionalidade da arquitetura para torná-las mais comprometidas com as necessidades humanas e menos com os imperativos econômicos do capital global, e também mais eficiente em restaurar o equilíbrio ecológico entre os mundos artificial e natural. Fernando Lara, planejador e acadêmico, sugeriu a reconsideração da tríade de Vitruvius, propondo redirecionar a atenção para os temas da Firmitas (tolerância, abrigo, proteção), ao invés da Utilitas (função), que dominou a produção arquitetônica no início do século passado, como também a Venustas (beleza, charme), que influenciou demasiadamente a produção arquitetônica das últimas décadas (Lara, 2001).

- Construir e promover ativamente uma ética humanista de desenho urbano. O ensaio de um projeto puramente estético é um bom exercício intelectual e tem um valor artístico por e em si mesmo. Sem a criatividade artística, a arquitetura e o desenho urbano se tornariam estéreis. Mas a arquitetura e o desenho urbano não se encontram
16 Conferência da Planners Network 2002 em Holyoke, MA: "New Visions for Historic Cities: Bridging Divides, Building Futures". 13 a 16 de junho. 
17 Por exemplo, a galeria Max Protetch em Nova York abriu em Janeiro de 2002 uma exibição, "A New World Trade Center: Design Proposals", mostrando propostas de mais de cinqüenta arquitetos do mundo inteiro (Architectural Record, 2002). Alguns meses depois, a oitava edição da Bienal Vienense de Arquitetura, entituala "Next", abriu em Setembro de 2002, mostrando vários projetos para substituir as torres gêmeas de Nova York. Fuksas, Isozaki, Piano e Hadid estavam entre os arquitetos que mostraram propostas. no âmbito das Artes Plásticas, já que suas produções são habitadas por pessoas reais e com necessidades cotidianas reais. No entanto, muitas exibições e propostas de projetos para a reconstrução do WTC são carentes de qualquer fundamento social crítico ou sequer tectônico sendo, no máximo, cascas vazias e bonitas. ${ }^{17}$ Deveriam as instituições de planejamento, como a ACSP e a APA, aplaudir a atitude arrogante de algumas estrelas da arquitetura (e escritórios de arquitetura) ao projetarem novos arranha-céus para o "marco zero" do WTC, desconsiderando o contexto local/global - como demonstrado por muitos dos projetos submetidos a essas exposiçôes? Deveriam eles, ao invés disso, apoiar propostas que visam espelhar o que havia no terreno do WTC, mostrando não só a falta de imaginação mas, pior ainda, a falta de uma prática reflexiva por parte dos projetistas, planejadores e construtores - como demonstrado por muitas das concepçóes apresentadas pela Comission for Redevelopment of Lower Manhattan em Julho de 2002? Eu sugeriria que a ACSP e a APA promovessem mais debates sobre as questóes e eventos ligados ao projeto e, se e quando chegarem a um consenso, fizessem declaraçóes públicas. Isto daria à comunidade de planejamento a oportunidade de contribuir mais substancialmente para o debate público e o direcionamento da política pública de desenho urbano.

- Transcender as dimensóes físicas e financeiras imediatas dos problemas de planejamento para atingir de uma forma mais justa, democrática e abrangente suas dimensões social, espacial e temporal. Os planos para a reconstrução do Baixo Manhattan não devem somente abranger um planejamento físico e financeiro que responda às necessidades e possibilidades da região sul de Manhattan, mas devem atender à reverberação social, espacial e temporal do que é planejado para o local do "marco zero", pensando na cidade, no país e no mundo. Reconhecer os (novos) sujeitos do planejamento em um mundo interconectado deve ser de suma importância e pode significar uma revisão de idéias. No caso do planejamento para o "marco zero", quem deveriam ser os sujeitos (reconstituídos) do planejamento? Na dimensão social, o povo local $e$ global. Na dimensão espacial, Manhattan, a Nova York metropolitana, os EUA $e$ o mundo. $\mathrm{Na}$ dimensão temporal, gerações atuais e futuras. Esses três eixos intrinsecamente interligados devem encontrar suas demandas incorporadas nos planos e projetos. Enquanto isso, devemos promover mais discussôes na esperança de encontrar algumas respostas para essas questões críticas.

- Na dimensão social, como podemos planejar para a população local $e$ global? Muito já foi dito sobre a necessidade de os planos do WTC promoverem oportunidades para grupos sociais locais. Marcuse, entre outros, propõe que a política de desenvolvimento econômico focalize as necessidades das pequenas empresas e a melhoria das condições educacional e econômica dos residentes de baixo poder aquisitivo (Marcuse, 2001, p.16). Dar atenção à igualdade social no projeto do WTC certamente prestará um grande serviço, muito necessário, a Nova York. Além disso, proveria uma excelente vitrine para a nação e o mundo. No entanto, para ser plenamente efetivo, o esforço não pode parar por aí. Planejamento social deve também incorporar a escala global. A compreensão da situação injustificável e insuportável de miséria que existe no mundo e a co-responsabilidade tanto do mercado quanto do capital global e da política externa dos EUA precisa aumentar. Então, medidas políticas e políticas públicas adequadas devem ser adotadas para melhorar a desigualdade econômica e de poder do mundo - e da nação e da cidade - e promover um desenvolvimento sustentável e igualitário que beneficie a maioria. 
- Na dimensão espacial, como podemos planejar para Manhattan, região metropolitana de Nova York, os EUA $e$ o mundo? É absolutamente essencial reconhecer que qualquer que seja a resolução espacial tomada para o "marco zero", ela estará imbuída de um significado muito além de sua presença física. Para conseguir, com responsabilidade, um projeto espacial que não sirva apenas a Manhattan, Nova York metropolitana e os EUA, mas também ao mundo, deve-se questionar o simbolismo representado pelas torres gêmeas. Nas palavras do filósofo Jean Baudrillard:

As torres gêmeas foram destruídas ou desabaram? Sejamos claros a respeito disto: as duas torres são tanto um objeto físico e arquitetônico, como um objeto simbólico (representando o poder financeiro e o liberalismo econômico global). O projeto arquitetônico foi destruído, mas o alvo a ser destruído, desde o início, foi o objeto simbólico. Poder-se-ia pensar que a destruição física trouxe a demoliçãa simbólica (...) Foi, na verdade, a queda simbólica que trouxe a queda física, não o contrário. (Baudrillard, 2002, p.47-8.)

Elas (as torres), um símbolo da onipotência, viraram, em sua ausência, o símbolo do possível desaparecimento de tal onipotência - possivelmente um símbolo mais forte. (Idem, p.51)

Espera-se que o novo projeto para o terreno do WTC não reincorpore a potência do capitalismo global e do neoliberalismo, como as antigas torres fizeram. Se tais objetivos foram atingidos como um resultado de um processo democrático e participativo de construção consensual, pode não ser otimismo ou ingenuidade demais pensar que esses poderes podem levar a certos níveis de controle humanitário global. Defendendo uma abordagem mais humilde, conscientizada e humanista do projeto, Marcuse argumenta:

O que deve ser feito no local não deve refletir a arrogância do poder mas, ao invés disso, a resiliência de uma vida vibrante e continuada, como também claramente a tristeza de sua (sic) história e a admissão de vulnerabilidade humana que é uma de suas liçōes. (Marcuse, 2001, p.15.)

- Na dimensão temporal, como podemos planejar para gerações presentes $e$ futuras? Para planejar para o presente e o futuro devemos promover um planejamento nas direçôes citadas anteriormente, isto é, o planejamento social que nutre justiça social; e o planejamento espacial atento não somente às necessidades físicas locais como também às necessidades simbólicas glocais. Além disso, um terceiro elemento deve receber atenção especial: o planejamento educacional. Educação não é só a chave para a melhoria da vida individual e social das geraçōes presentes e futuras. Educação é também a ferramenta com a qual as geraçōes presentes e futuras podem sobrepujar a mentalidade estreita que levou o mundo a esse confronto sem sentido entre "Jihad e McWorld", no qual aparentemente estamos presos hoje. A educação é, por fim, o instrumento-chave para forjarmos uma convivência mundial pacífica e frutífera. Educação é necessária em todos os níveis da sociedade, e é necessária antes mesmo de nos voltarmos ao problema do projeto, como sugerido por Muschamp:

De alguma forma, a idéia de que as questôes históricas surgidas em setembro último podiam ser resolvidas pela arquitetura, planejamento e projeto ganharam força. Elas não podem, nem pelos mais talentosos profissionais da área (...) O problema não é de relaçôes 
Clara Irazábal é professora da School of Policy, Planning and Development da University of Southern California, Los Angeles, Califórnia. E-mail: irazaba@@usc.edu ção em agosto de 2003. públicas. Nem é uma questão de projeto. É um problema educacional. Ele envolve criar um clima de idéias suficientemente robustas para apoiar o surgimento de soluçôes arquitetônicas para o futuro mais adiante. Os técnicos das agências de desenvolvimento estarão impotentes para educar o público até que assumam a tarefa muito mais assustadora de educarem a si próprios. (Muschamp, 2002.)

Recapitulando, o modelo da arquitetura e planejamento modernistas materializados no complexo PI explodiu segundo dois sentidos associados ao termo: a teoria moderna a ele subjacente foi levada a descrédito; e ele literalmente sucumbiu violentamente como resultado de uma pressão de dentro pra fora, isto é, dos problemas sociais reais que o complexo concentrava e agravava para seus residentes. De sua parte, o modelo materializado pelo WTC tanto explodiu quanto implodiu. Explodiu, porque a teoria por trás dele foi levada a descrédito devido a sua ênfase excessiva na monumentalidade e simbolismo do poder econômico em detrimento das necessidades do povo. O WTC também implodiu, desmoronando para dentro devido a uma pressão externa, isto é, no nível material, devido à colisão dos jatos e, no nível conceitual, dos problemas sociais reais que o complexo tanto simbolizava quanto efetivamente alimentava e causava no mundo. Jencks havia dito que depois que as paredes do PI se desmancharam, atravessamos o portal do complexo e contraditório mundo da arquitetura pós-moderna. No entanto, somente quando as paredes - e pessoas - do WTC ruíram diante do mundo, no primeiro show de terrorismo transmitido mundialmente ao vivo, é que o caos, crueldade e niilismo da pós-modernidade explodiram/implodiram sobre todos nós, ricos e pobres, negros e brancos, religiosos e seculares, para o pior. Há, no entanto, projetos criativos e construtivos, que vêm reagindo à deficiência de oportunidades emancipatórias e de significado nos projetos hegemônicos, tanto da modernidade como da pós-modernidade (Ley, 2000, p.622-3). São esses os pontos nos quais o planejamento e os planejadores devem se inspirar e ajudar a crescer. $\mathrm{O}$ mundo mudou. Poderá o planejamento pós $11 / 9$ mudar?

Tradução: Diogo Lana Monte-Mór

\section{REFERÊNCIAS BIBLIOGRÁFICAS}

ANGOTTI, T. "Planning to rebuild: the issues ahead." Planners Network, n.149(1), p.16-7, 2001.

ANNAN, K. "From Doha to Johannesburg by way of Monterrey: how to achieve, and sustain, development in the 21st century." Palestra proferida na London School of Economics and Political Science. Londres, 25/2/2002.

ARCHITECTURAL RECORD. The Max Protetch Gallery Exhibit. "A New World Trade Center: Design Proposals", mar. 2002.

BAUDRILLARD, J. The mirror of production. Saint Lois: Telos Press, 1975.

CASTELLS, M. "The world has changed: can planning change?" In: ACSP ANNUAL MEETING. 1990. Proceedings... Austin, Texas, 2/11/1990.

CRYPTOME. "Interesting comments on WTC Architecture and History." Acesso em $2001<$ http://cryptome.org/wtc-collapse.htm>

DALLMAYR, F. "Lessons of September 11." Theory, Culture \& Society: Explorations in Critical Social Science, v.19, issue 04, ago. 2002. 
GAUSE, D. G.; LAWRENCE, B. "User-Driven Design: incorporating users into the requirements and design phase." Acesso em $2001<$ http://www.stickyminds.com/sitewide. asp? ObjectId=2659\&Function=DETAILBROWSE $\&$ ObjectType=ART $>$ (Originamelmente publicado na revista STQE, jan./fev. 1999.)

GLANCEY, J. "Reaching for the sky: on the passion for tall buildings and what Tuesday's events could mean for the future shape of our cities." The Guardian, 15/9/2001. Acesso em <http://www.guardian.co.uk/saturday_review/story/0,3605,552020,00.html>

HARVEY, D. The condition of postmodernity. Oxford: Blackwell, 1989.

IRAZÁBAL, C. "Architecture and the production of postcard images: invocations of tradition vs. critical transnationalism in Curitiba." In: ALSAYYAD, N. (Ed.). The end of tradition. Londres: Routledge, 2003.

JACOBS, J. M. "The global domestic: the highrise postcolonially considered." CED Architecture Lecture Series, University of California, Berkeley, 2000. (1 Videocassete, 76 min., VHS.)

JENCKS, C. El lenguaje de la arquitectura postmoderna. Barcelona: Editorial Gustavo Gili, 1981.

. Late-Modern Architecture. Nova York: Rizzoli International Publications, 1980.

JENKS, H. "September 11. One year later: Mary Dudziak reflects on the transformative nature of 9/1/01." El Boletin, Center for American Studies \& Ethnicity and the Program in American Studies \& Ethnicity, University of Southern California, 6, 2002.

LARA, F. “Depois do World Trade Center?" Vitruvius, 2001. Acesso em <www.vitruvius.com.br>

LEY, D. "Postmodernity". In: JOHNSTON, R.J. (Ed.). The Dictionary of Human Geography. 4.ed. Malden, MA: Blackwell Publishers, 2000. p.622-3.

LYNCH, K. "City and regional planning." In: BANERJEE, T.; SOUTHWORTH, M. (Eds.). City sense and city design. Cambridge, MA: The MIT Press, 1973.

MACDONALD, D. Democratic Architecture: practical solutions to today's housing crisis. Nova York: Whitney Library of Design/Watson-Guptill Publications, 1996.

MARCUSE, P. "Planning after September 11: the issues in New York." Planners Network, n.150, p.36-9, 2002.

. "Urban life will change: proposals for rebuilding." Planners Network, n.149(1), p.15-6, set./dez. 2001.

MUSCHAMP, H. "New Trade Center idea: move bulk to West St." New York Times, 25/7/2002.

NEWMAN, O. Defensible space; crime prevention through urban design. Nova York: Macmillan, 1972.

SASSEN, S. "Governance hotspots: challenges we must confront in the post-September 11 World.” Theory, Culture \& Society: Explorations in Critical Social Science, v.19, issue 04 , ago. 2002.

SASSEN, S.; DORFMAN, A.; CHOMSKY, N.; EL SARRAJ, E.; RABIN, Y.; PLATKIN, D.; MOORE, M.; GALEANO, E. “The Seventh Generation.” Planners Network, n.149(1), p.18-20, 2001.

SCHOOL OF JOURNALISM AND THE CONGRESS FOR THE NEW URBANISM. "Rebuilding Lower Manhattan: A discussion." The Terner Series on Urban Development, University of California at Berkeley, 26/9/2001.

SEGRE, R. "World Trade Center (1973-2001): fragilidade de um ícone urbano.”Vitruvius. Acesso em 2001 <www.vitruvius.com.br> 
D O P R U I T T - I G O E A O W O R L D T R A D E C E N T E R

SIM, S. (Ed.). The Routledge Critical Dictionary of Postmodern Thought. Nova York: Routledge, 1999.

SPEAKS, M. "It's out there: the formal limits of the American avant-garde." Architectural Design, Londres, 68(5/6): 26-31, maio/jun. 1998.

WIKIPEDIA. "Minoru Yamasaki." Acesso em 2001 <http://www.wikipedia.com/wiki/Minoru_Yamasaki>

WIKIPEDIA. “World Trade Center.” Acesso em 2001<http://www.wikipedia.com/wiki/World_Trade_Center>

WISOTZKI, R. "Rafael Courtoisie busca una gran revelación en una página. A las torres de palabras no las derriba un avión.” El Nacional, Caracas, 24/11/2001.

A B S T R A C T This article proposes, amidst post modernity concepts, the resemblance between the destruction of two major symbols of modern planning and architecture: the Pruitt-Igoe (PI) housing project and the World Trade Center (WTC). The author states that both events were not only physical (the PI implosion having been a planned event in contrast to the unplanned WTC destruction) but also the materialization of the fall of the modern thinking embodied in them. Contrary to most ideas, the author proposes that by 09/11 the world had already changed, and the WTC destruction only represented that change. Along with these arguments, the author also proposes a series of changes in the planning and architectural fields, as well as new conceptions towards contemporary project planning, such as the projects for Ground Zero.

K E Y W O R D S Modern architecture; post-modernity; Pruitt-Igoe; World Trade Center. 